\title{
Chronic migraine is not associated with cerebellar infarct-like lesions
}

\author{
A Meilan, E Santamarta, A Saiz, D Larrosa, E Cernuda, J Pascual ${ }^{*}$ \\ From The European Headache and Migraine Trust International Congress \\ London, UK. 20-23 September 2012
}

\section{Introduction}

Two general population studies $[1,2]$ have found that migraine in general, and especially women with aura, has an increased risk of cerebellar infarct-like lesions by MRI. In addition, there was a trend for higher risk of cerebellar lesions in those migraine subjects with a higher migraine attack frequency, which would have obvious clinical and management implications.

\section{Objective}

To determine whether chronic migraine patients are at increased risk of cerebellar infarct-like lesions on MRI.

\section{Methods}

After signed informed consent, brain MRIs were obtained in 50 women from our headache clinic meeting chronic migraine according to 2006 IHC-II revised criteria. Six had a history of migraine with aura attacks and 19 meet overuse criteria. Their ages ranged from 16 to 63 years (mean 40.9 years) and the length of chronic migraine range from 6 months to 27 years (mean 7.5 years). At least 11 patients had a minimum of one vascular risk factor and the prevalence of right to left shunt with transcranial echo was $58 \%$. Brain MRIs were acquired on a 1.5T unit Signa LX 9.1 (General Electric Systems, USA). Protocol includes whole brain weighted images in saggital T1 (5 mm slices), axial FLAIR T2 $(3 \mathrm{~mm})$ and combined proton density and T2 fast spin echo $(3 \mathrm{~mm})$. Two independent neuroradiologists carefully analysed all the cerebellar images.

\section{Results}

After an in depth review of all posterior fossa slices, we were unable to find even one cerebellar infarct-like lesion in any of these chronic migraine patients.

\section{Conclusions}

Following the same MRI methodology of the previous studies, we demonstrate that, at least for migrainous women, there is no relationship between migraine frequency and the presence of cerebellar infarct-like lesions. Therefore, at least for the cerebellum, frequency of migraine attacks itself does not seem to be a factor increasing the risk of vascular brain lesions. These findings call for caution when extrapolating findings from the general population into current clinical practice.

Supported by the PI11/00889 FISSS grant (ISCIII)

Published: 21 February 2013

\section{References}

1. Kruit, et al:. JAMA 2004, 291:427-34.

2. Scher, et al.. JAMA 2009, 301:2563-2570.

\section{doi:10.1186/1129-2377-14-S1-P137}

Cite this article as: Meilan et al.: Chronic migraine is not associated with cerebellar infarct-like lesions. The Journal of Headache and Pain 2013 14(Suppl 1):P137.
Submit your manuscript to a SpringerOpen ${ }^{\circ}$ journal and benefit from:

- Convenient online submission

- Rigorous peer review

- Immediate publication on acceptance

- Open access: articles freely available online

- High visibility within the field

- Retaining the copyright to your article

Submit your next manuscript at $>$ springeropen.com
(C) 2013 Meilan et al; licensee Springer. This is an Open Access article distributed under the terms of the Creative Commons Attribution License (http://creativecommons.org/licenses/by/2.0), which permits unrestricted use, distribution, and reproduction in any medium, provided the original work is properly cited. 